\title{
EDITORIAL
}

\section{Centre for Precision Manufacturing}

\author{
Xichun Luo ${ }^{1}$
}

Published online: 4 September 2020

(c) International Society for Nanomanufacturing and Tianjin University and Springer Nature Singapore Pte Ltd. 2020

The Centre for Precision Manufacturing (CPM) is an internationally leading research centre for advanced manufacturing. The centre researches and develops materials, processes, tools, machinery, and numerical modelling techniques for improving economic and technical performance of materials and manufacturing processes with advanced precision, micro- and nano-manufacturing techniques. CPM is one of the most successful centres in Europe in attracting external funding (over $£ 40$ million) to conduct industry-relevant research. The centre led the EU FP6 flagship integrated project MASMICRO, one of the largest-ever funded EU projects in the EU NMP theme ( $€ 21.4$ million budget and 36 partners from $13 \mathrm{EU}$ countries) which led to a series of new design and manufacturing solutions in dealing with materials, size effects, micro-handling, inspection, benchtop machine designs, and manufacturing systems integrations and being evaluated as "the project could help Europe become the world leader in mass-manufacture of microcomponents", FP7 Polytubes project ( $€ 5.0$ million, 18 partners), FP7 Micro-FAST project ( $€ 7.5$ million, 18 partners) and UK EPSRC flexible manufacturing programme Micro3D project ( $£ 2.1$ million, 10 partners). The centre’s staff played key roles in EPSRC/TSB funded SAMULET Project, EU FP7 M3-2S, and ManuCloud Projects. Currently, the centre is leading a H2020 Fast-SMART project ( $€ 6.8$ million, 13 partners) and a UK EPSRC future manufacturing systems project SMART-MAN ( 22.8 million, 11 partners) and plays a key role in three $\mathrm{H} 2020$ projects with a research folio of over $£ 12$ million.

The Centre for Precision Manufacturing is proud of setting the agenda in terms of its innovative approach. Our seminal work in micromanufacturing and hybrid machining has now been recognised internationally thanks to the two popular books published by Elsevier in 2010 (2nd edition in

Xichun Luo

xichun.luo@strath.ac.uk

1 University of Strathclyde, Glasgow, UK
2015) and 2018. The centre is comprised of three research groups, including:

- Precision Forming and Micro-manufacturing, led by Prof. Yi Qin.

- Precision and Ultra-precision Machining, led by Prof. Xichun Luo.

- Light Metals Advanced Technology: led by Dr. Andrzej Rosochowski.

Professor Yi Qin is a Professor in Manufacturing Technology and Systems, Director of the Centre for Precision Manufacturing, Editor-in-Chief of the Journal of Manufacturing Review, Associate Editor of the International Journal of Lightweight Materials and Manufacture, Secretary to the Committee of the UK University Manufacturing Engineering Consortium, and a Fellow of the Institution of Mechanical Engineers. Professor Qin has published over 250 technical articles on various subjects in the fields of materials, manufacturing, and numeric modelling, including a book "Micro-Manufacturing Engineering and Technology" (published by Elsevier, 1st edition in June 2010, and 2nd edition in June 2015), and five journal special issues. Professor Qin has delivered keynote speeches and invited lectures at more than 30 international conferences/workshops. He has reviewed technical papers for more than 20 international journals and has been a member of the scientific committee for more than 40 international conferences. He was the Chair of the 4th International Conference on New Forming Technology (ICNFT) (Glasgow, August 2015), and Co-Chair of the 5th ICNFT (Bremen, Sept. 2018).

Professor Xichun Luo is a Professor in Ultra-Precision Manufacturing and Technical Director of Centre for Precision Manufacturing. He is an Elected Fellow of the International Society for Nanomanufacturing, the International Academy of Engineering and Science and the International Association of Advanced Materials. He is on the Scientific Committee of the European Society of Precision Engineering and Nanotechnology and Technical Committee of Advanced Forming Research Centre. He is an 
Associate Editor for Proceedings of IMechE Part C: Journal of Mechanical Engineering Science, Journal of Micromanufacturing and Mechanical Sciences, and an editorial board member for Micromachines, Journal of Nanomanufacturing and Metrology and International Journal of Extreme Manufacturing. He is a member of EPSRC Peer Review College and the Past-President of The Chinese Automation and Computing Society in the UK. He has published over 120 papers in peer-reviewed highly ranked journals, two books, and five invited book chapters. He has delivered over 20
Keynotes and plenary lectures at top precision engineering international conferences, research institutes, and companies. He organised two IEEE International Conferences in Automation and Computing (ICAC 2014 and ICAC2015) as a conference chair. He won the Institution of Mechanical Engineers (IMechE) 2015 Ludwig Mond Prize for his seminal work in application of digital technology in micro- and nano-manufacturing. 